\title{
INTERCULTURAL OR NOT? BEYOND CELEBRATION OF CULTURAL DIFFERENCES IN MISCOMMUNICATION ANALYSIS ${ }^{1}$
}

\author{
Srikant Sarangi
}

\section{Introduction}

The basic question this paper addresses is: What should be the underlying purpose of intercultural analysis? Is the purpose to explain conversational mismatches in terms of cultural differences in an abstracted way? Or is the purpose to make an attempt to understand the complex institutional processes in which the shifting nature of 'culture' is embedded? As the main title suggests, I primarily address these issues by focusing on what characterises intercultural communication as '(not) intercultural'. The subtitle - 'celebration of cultural differences in miscommunication analysis' - applies to two aspects of intercultural analysis: (i) how 'culture' is used as an analytic construct to study miscommunication, and (ii) how certain researchers indulge in the 'analytic stereotyping' of intercultural encounters as mainly characterised by the cultural differences present. ${ }^{2}$

The first part of this paper (comprising section 2) offers a by no means exhaustive critical review of two specific types of intercultural communication analysis, i.e., one that can be situated within cultural anthropology and another with a more sociolinguistic and pragmatic orientation. By pointing at a dominant trend of 'thematisation of cultural differences', I offer a critique of an essentialist view of 'culture' in these types of intercultural analysis, thus extending a position taken earlier (Roberts \& Sarangi 1993). The second part of the paper (comprising sections 3,4 , and 5) starts with a call for a discourse orientation to the analytic concept of 'culture', which is followed by an analysis of situated intercultural data in the gatekeeping situation of selection interviews. This leads me to revisit the notion of 'interculturality' from a cultural-theoretic perspective, with particular reference to migrants' experience in contemporary multicultural societies.

\footnotetext{
${ }^{1}$ A condensed version of this paper was first presented at the fourth International Pragmatics Conference, Kobe, July 1993, under the title 'Beyond celebration of miscommunication: critical perspectives on intercultural communication'. I am very thankful to Jan Blommaert, Michael Meeuwis, and Stef Slembrouck for their suggestions on an earlier draft.

${ }^{2}$ Elsewhere (Sarangi 1992) I elaborate this notion of 'analytic stereotyping' with reference to the study of native-nonnative discourse, where misunderstandings are explained by appealing to the linguistic deficiency on the part of the nonnative speakers.
} 


\section{Miscommunication and culture as represented in two traditions}

\subsection{Intercultural analysis from a cultural-anthropological perspective}

'Intercultural communication' is the preferred term among some cultural anthropologists to describe the study of interaction - generally in the face-to-face informal setting - between individuals representing different 'cultures' (e.g., Asante \& Gudykunst 1989; Brislin 1981; Casmir 1978; Condon \& Yousef 1975; Gudykunst 1983, 1991; Gudykunst \& Kim 1984, 1988; Prosser 1978a, 1978b; Samovar \& Porter 1991; Samovar et al. 1981). Asante et al. (1979) divide this tradition into two categories on the basis of the preferred research goals. The first group of researchers, whom they label 'cultural dialogists', emphasise the need to develop a humanistic view of communication theory and practice that would promote world understanding. The second school, referred to as 'cultural criticism', is guided by the principle of conflict and tries to identify points of conflict between individual cultures as researchable issues. These two schools, in my view, are not exclusive to one another as both of them share an interest in the study of 'differences across cultures'. Although these studies acknowledge the role of language in the manifestation of cultural differences, the underlying assumption is that cultural problems are more significant than linguistic problems. As Prosser (1978a: 102) maintains:

"Actually, though the individual language and culture are tightly linked, and therefore do cause important barriers for intercultural communication and for cultural spokespersons, the language problems may be less severe than other cultural barriers; for example, perceptions, attitudes, stereotypes, prejudices, beliefs, values, and thought-patterning itself."

This view suggests, on the one hand, that there is a link between culture and language in a Whorfian sense, but on the other hand, that 'language' is to be kept analytically separate from 'culture'. These two assumptions amount to saying that language is contained within and reducible to culture, thus denying language its reality-constructing role (as will also be made clear in section 3.1).

Moreover, individual 'cultures' are seen as unified and homogeneous entities, and, by extension, communicative difficulties are invariably explained in terms of cross-cultural differences. By equating 'culture' with thoughts, feelings, values, and beliefs of individuals, and by assuming that it exists in the heads of individuals, this notion of culture misses the dynamics of social life. According to Wuthnow et al. (1984: 4), in this tradition of analysis, 'culture' comes to be treated as the least observable category of non-behaviour:

\footnotetext{
"Culture is that residual realm left over after all forms of observable human behaviour have been removed. It consists of the inner, invisible thought life of human beings either as individuals or in some difficult-to-imagine collective sense, as in notions of 'collective purpose', 'shared values', and 'intersubjective realities'. What people actually do, how they behave, the institutions they construct [...] however, are not a part of culture."
}

This tradition can thus be said to neglect the complex and multi-layered 'cultural' outlook of individual interacting participants. Also, with its heavy reliance on examples drawn from hypothetical contact situations, it can offer very little insight 
into what really goes on in the context of situated discourse. Although these studies claim to be concerned with interactions at the situated level, they themselves rather run the risk of giving rise to cultural stereotypes by overlooking individual differences and other situational variables surrounding the intercultural communication event. In other words, in these studies the individual participants are considered to represent their respective 'cultures' and thus cease to be individuals in their own right. ${ }^{3}$ Consequently, while the analysis of the intercultural event is made on a collective scale, the creation of a hypothetical individual is a means toward arriving at generalisations about 'cultures'.

\subsection{Intercultural analysis from sociolinguistic and pragmatic perspectives}

\subsubsection{The interactional-sociolinguistic perspective}

Works by, among others, Gumperz (1978, 1982); Gumperz \& Tannen (1979); Scollon \& Scollon $(1980,1983)$ can be seen as a reaction to the above mentioned cultural-anthropological tradition which pays very little attention to linguistic and interactional data. Two of the key assumptions which underlie the interactionalist research tradition are: (i) ethnicity and different cultural backgrounds determine speakers' discourse strategies (different ways of speaking, different ways of structuring information, etc.); (ii) different discourse strategies and communicative styles can lie at the heart of interethnic misunderstandings.

With regard to these key assumptions, we notice strong resonances between this tradition and the cultural-anthropological tradition reviewed in section 2.1, as they continue to share a belief that communicative problems can be accounted for in terms of cultural differences. But unlike the cultural-anthropological tradition which hypothesises about potential problems on the basis of cross-cultural differences, the interactional-sociolinguistic tradition locates communicative problems in observed linguistic data. This tradition thus deserves credit for having produced fine-grained analyses of naturally occurring intercultural encounters.

It is beyond the scope of this paper to review the accusations of ethnocentric analytic bias hauled against the Gumperzian analysis of miscommunication. ${ }^{4}$ What concerns me more is the way in which this framework overemphasises the explanatory power of 'contextualisation cues' in relation to understanding 'culture'. Consider what Gumperz (1992: 51-52) writes in a recent paper titled 'Contextualisation revisited':

\footnotetext{
${ }^{3}$ A related paradox arises, however, as these studies lead to a proliferation of 'how to' literature emphasising 'intercultural adjustment', 'adaptation through awareness' etc. aimed at real-life individuals.
}

${ }^{4}$ Singh et al. (1988) and Kandiah (1990) allege that there is a strong ethnocentric bias in the interactional-sociolinguistic tradition. My impression, however, is that these critics' alternative explanations from the viewpoint of the 'cultural other' maintain a generic 'cultural principle' (for a fuller discussion, see Sarangi 1994). 
"The notion of contextualization has significant implications for our understanding of what culture is. Traditionally, anthropologists speak of culture in terms of shared meaning or shared interpretive practices or shared cognitive structures. Our discussion points to the importance of shared typifications that enter into the signaling and use of activity types in interaction, as well as systems of contextualization conventions. In contrast to the established, commonly accepted idealizations, such interactively defined notions of culture can be studied by empirical means [...]."

This view no doubt highlights the importance of framing encounters through 'contextualisation cues' on the one hand, and the fluid nature of social/cultural identity in discoursal settings on the other. While not denying the significant role contextualisation cues play in the construction of an interactional context, I envisage insuperable problems in assigning contextualisation cues an overpowering explanatory value when it comes to interpreting participants' cultural identities in an intercultural encounter. The problem stems from the fact that there is more to 'contextualisation cues' than 'culture'. As Shea (this volume) shows, inferences and contextualisation strategies are also mediated by situational and societal structures, and this makes it particularly difficult to isolate the 'cultural' in contextualisations.

\subsubsection{The cross-cultural pragmatic perspective}

Staying close to the contrastive-linguistic tradition, studies such as Blum-Kulka \& Olshtain (1984); Brown \& Levinson (1987); Blum-Kulka et al. (1989) focus on how normative patterns for linguistic activities contrast across cultures. These cross-cultural comparisons have been carried out in two ways. First, some authors investigate how a specific linguistic activity is carried out in culturally different speech communities. Brown \& Levinson's (1987) comparative account of how politeness strategies are realised differently in different languages is a classic example of this kind of cross-cultural enquiry. ${ }^{5}$ Secondly, some studies look at the different realisations of, for example, a particular speech act in a second language by learners with different mother tongues. The Cross-Cultural Study on the Speech Act Realization Patterns project, as reported by Blum-Kulka \& Olshtain (1984), is a case in point as it attempts to establish the similarities and differences between native and nonnative realisation patterns of 'requests' and 'apologies'. The problem is that dealing with cultural differences in doing cross-cultural comparisons does not get one nearer to the point of 'intercultural contact'. Moreover, such a comparative analysis does not help to explain potential sources of 'intercultural miscommunication'.

Outside the realm of contrastive pragmatics is the work by Thomas (1983), who suggests that mismatches in intercultural settings can be categorised as either 'pragmalinguistic' (the inappropriate transfer of speech act strategies from first to target language) or 'sociopragmatic' (cross-culturally different assessments of social parameters affecting linguistic choice). These categories are self-explanatory and

${ }^{5}$ It is worth pointing out that 'cross' often presupposes an oppositional trend. It asks the question as to how $x$ differs across cultures, i.e., how $x$ is manifested in a number of separate cultures with $n$ number of differences and $n^{\prime}$ number of similarities. 
therefore helpful, but a pragmatic analysis of this kind, in much the same way as interactional-sociolinguistic analyses, takes 'culture' for granted, forges a strong link between 'language use' and 'culture', and therefore pays little attention to individual variations. ${ }^{6}$

\subsection{The burden of 'cultural differences' in miscommunication analysis}

Wittgenstein once said, when put on an unbalanced diet of examples philosophy suffers from deficiency diseases. This medical metaphor can be extended to describe quite aptly the deficiency syndrome in the types of intercultural research reviewed above. The deficiency I allude to relates to these analysts' preoccupation with diagnosing and treating miscommunication among individuals in 'cultural' terms. In the remainder of this paper my main concern will be with what particular goals this type of analysis of miscommunication serves, and with suggesting possible alternatives.

In communication research generally, there seems to be some agreement among researchers that it is through the study of communicative breakdown that we understand how successful communication happens (Gumperz \& Tannen 1979; Stubbs 1983). Indeed, in a recent volume titled 'Miscommunication and Problematic Talk' Coupland et al. (1991: 2) undertake to "rescue 'miscommunication' from its theoretical and empirical exile, and explore its rich explanatory potential in very diverse contexts". ${ }^{7}$ Applied to the context of intercultural miscommunication, however, this heuristic value attached to miscommunication seems to take on a peculiar shape. Rather than studying miscommunication in its own terms or for the undoubtedly valuable sake of coming to grips with communicative success, studies of the type identified in the previous subsections use 'miscommunication' to reify cultural differences. Put very strongly, it is through the occurrence of miscommunication that cultural differences become real and take on a life of their own. This leads to what I call 'analytic stereotyping' of intercultural events. Analysts operate with a prior definition of the situation and its participants as (inter)cultural and subsequently play upon a principle of cultural differences in accounting for instances of miscommunication. ${ }^{8}$ The risk of circularity attached to this analytic

\footnotetext{
'A possible alternative (suggested in Sarangi 1994) focuses on Levinson's (1979) notion of 'activity type' in order to show how the existence of layers of normative rules in gatekeeping situations makes communicative breakdowns possible, whether or not participants share the same 'cultural' norms. This implies a shift from 'culturally-determined' discourse strategies (in the heads of people) to 'socio-culturally' governed 'activity types'.

${ }^{7}$ For a detailed discussion of several interpretations of the notion 'miscommunication' and its many variants, see Coupland et al. 1991.

${ }^{8}$ Consider here the analytic basis of intercultural studies carried out in the workplace setting (for example, Moran \& Harris 1991 and Moran \& Riesenberger 1994). Unlike in the anthropologically oriented work reviewed, the focus is on the denial of a problem by claiming that cultural differences do not necessarily mean barriers; they can become bridges to understanding and to the enrichment of our lives. By contrast with its metaphorical use in this paper, these workplace studies realise the 'celebration of cultural differences' in a literal way.
} 
practice should be clear: If we define, prior to analysis, an intercultural context in terms of 'cultural' attributes of the participants, then it is very likely that any miscommunication which takes place in the discourse is identified and subsequently explained on the basis of 'cultural differences'. ${ }^{9}$ This mode of analysis, which forces an analytic separation between language and culture, also presupposes that there are clearly demarcated boundaries which divide one homogeneous cultural group from another. Such a unified, monolithic view of 'culture' goes hand in hand with the thematisation of cultural differences.

\section{Rethinking 'culture' in multicultural societies}

\subsection{A discourse orientation to the analytic concept of 'culture'}

The discussion in the foregoing section makes clear the need for an orientation that can overcome the analytic separateness between language and culture. In this respect Sherzer's (1987) discourse-centred approach to language and culture is a very appealing alternative. As he points out, discourse has to be considered as the concrete expression of the language-culture relationship, because it is discourse that "creates, recreates, focuses, modifies, and transmits both culture and language and their interaction" (1987: 295). Sherzer's view is able to offer serious advantages if applied to analysing intercultural encounters. It allows to move away from the tradition of 'identifying' miscommunication at the 'linguistic' level, and then 'explaining' the phenomenon of miscommunication at the 'cultural' level.

Critical discourse analysis (Fairclough 1985, 1988) seems very apt to offer the tools for implementing the discourse-centred approach in the context of intercultural studies. Critical discourse analysis pays adequate attention to the dialectic relationships between social structures and linguistic practices. It holds that discourse has effects upon social structures, and is at the same time determined by them. This has implications for the study of encounters in multicultural settings in the sense that these settings are a typical locus where the micro and the macro levels intersect. Critical discourse analysis also draws attention to how actual discourse is determined by 'orders of discourse' (Foucault 1984), which are ideologically shaped by power relations in social institutions and society as a whole. Consider, for instance, any modern western society with its unique history of the migrant phenomenon and the accompanying discourses of 'racism' and 'discrimination' to mark the changing nature of social relationships between members of the minority and majority groups. In the context of intercultural analysis, then, one will be able to address the question as to how issues like 'racism' and 'discrimination', which are connected to such institutionalised orders of discourse, can become conversational topics in situated talk between members of minority and majority groups. For purposes of analysing my intercultural data in the institutional setting (see section 4), I shall adopt an integrated framework which

\footnotetext{
${ }^{9}$ This line of critique has also been taken up by Blommaert (1991), and it is similar to what Henley \& Kramarae (1991) refer to as the 'two cultures' approach to language and gender studies. For Henley \& Kramarae, such an approach explains away the inherent power struggle in cross-gender communication as 'mere' communicative differences.
} 
brings together the micro-macro concerns of critical discourse analysis and Sherzer's view about the language-culture relationship.

\subsection{From 'what is culture' to 'what we do with culture'}

Next to overcoming the culture-language analytic separateness and being aware of the significance of the structure-agency relationships, we are now faced with tackling an essentialist view of 'culture'. The conceptualisation of culture as people embodying a unified belief or value system is increasingly being regarded as a myth, since it misleadingly portrays social groups as 'ideational islands'. Partly fuelled by a sociological critique, there is now a sense of uneasiness among some contemporary anthropologists regarding 'what culture is', addressing the related problem "of whether the concept has any real analytic importance, and of how to recognise the existence and boundaries of distinct cultures" (Drummond 1986: 215). Clifford \& Marcus (1986: 19), for instance, point out that 'culture' cannot be represented as a "unified corpus of symbols and meanings that can be definitely interpreted". ${ }^{10}$ Implied here is a critique of the traditional anthropological preoccupation with searching for cultural sharedness at the expense of diversity and contradictions within a given society. Barth's (1989: 122) recent study of Bali 'culture', which exposes the 'multiplicity of partial and interfering patterns', raises fundamental questions about the nature of cultural coherence:

"Instead of trying to make our theories embrace what is there, we are led to picking out some small, distinctive pattern in this confusing scene, and applying our ingenuity to salvaging a (functionalist) holism by constructing (structuralist) isomorphies and inversions of this randomly chosen pattern, as if it encoded a deeper connectedness."

Barth hereby warrants that anthropology needs to reshape its assumptions about 'culture', particularly in response to recent reflexive and deconstructionist critiques. A promising alternative lead comes from Thornton (1988: 26) who, likewise rejecting the notion of a fixed inheritance of shared meanings, suggests to ask not 'what culture is' but 'what culture does':

"Part of the problem that besets our current efforts to understand culture is the desire to define it, to say clearly what it is. To define something means to specify its meaning clearly enough so that things which are like it can be clearly distinguished from it."

Taking this line of thinking further, Street (1993: 25) treats 'culture' as a 'verb' and points out how people put 'culture' to different uses:

\footnotetext{
${ }^{10}$ Gramsci (1981: 193) has drawn our attention to the danger inherent in a view of 'culture' as 'memory' when he says: "We need to free ourselves from the habit of seeing culture as an encyclopaedic knowledge, and men [sic] as mere receptacles to be stuffed full of empirical data and a mass of unconnected raw facts, which have to be filed in the brain as in the columns of a dictionary, enabling their owner to respond to the various stimuli from the outside world."
} 
"Indeed, the very term 'culture' itself ... changes its meanings and serve different often competing purposes at different times. Culture is an active process of meaning making and contest over definition, including its own definition."

In a similar vein, Eisenstadt (1989) addresses the issue of the mutual determination of 'culture', 'social structure' and 'social behaviour'. This view opposes the 'order-maintaining' and 'order-transforming' functions of culture. Eisenstadt quotes Peterson (1979: 159):

\begin{abstract}
"While it [culture] was once seen as a map of behaviour it is now seen as a map for behaviour. In this view, people use culture the way scientists use paradigms [...] to organise and normalise their activity. Like scientific paradigms, elements of culture are used, modified, or discarded depending on their usefulness in organising reality [...] as nearly equivalent to the term ideology, but without the latter's pejorative connotations [...] Sociologists now recognise that people continually choose among a wide range of definitions of situations or fabricate new ones to fit their needs." (original emphasis)
\end{abstract}

A non-essentialist and action-oriented perspective on 'culture' enables analysts interested in intercultural miscommunication to take on board the complexities related to the uses and functions of 'culture' in contemporary societies (cf discussions in Hall 1981, 1990). The notion of 'culture' is very much a contested one in many modern societies, as both dominant and dominated groups often resort to the culture card in managing their power-maintaining and power-acquiring purposes. So, in analysing encounters between the dominant and dominated groups in a multicultural society, we need to subscribe to a dynamic view of 'culture'. Rather than attribute communicative breakdown to cultural differences in an unproblematic way, the analysis of intercultural encounters should aim at coming to grips with the workings of 'culture' in individuals' discourse practices, as will be attempted in the data analyses in the following section.

\title{
4. Intercultural miscommunication analysis: Towards a dynamic model
}

In this section I shall illustrate the discussions in sections 2 and 3 by presenting some situated data and by evaluating competing lines of explanation. The data I analyse below concern gatekeeping situations of selection interviews. The interviewees can be characterised as younger Asian migrants who are typically different from the 'first' or 'second' generation migrants in terms of socio-educational background, professional ambitions, etc. The first example is taken from a selection interview for a motor mechanics training course. The interviewer (I) is British and the interviewee (R) is of Asian origin. What I have just provided is an identification of the context in terms of its intercultural dimension, highlighting the different cultural attributes of the participants. But such a characterisation of this discourse situation is selective since the participants' identities are fundamentally multi-faceted. The interviewee is not only a member of the minority culture, he also enjoys less situational power as far as the 'interview game' is concerned, and, moreover, as a nonnative speaker of English, he may be lacking in linguistic knowledge. By contrast, the interviewer is not only a native speaker of English, he is also a member of the majority culture, and has the situational power in the 
interview context. Thus, an alternative to the intercultural characterisation of this discourse setting is a characterisation which foregrounds the linguistic and situational asymmetries. Let us now consider example (1), and assess the different lines of explanation these alternative characterisations of the setting can offer. ${ }^{11}$

\section{Data Example 1}

01 I: right $\mathrm{mhm}$ hm what kind of driving have you been doing in England

02 R: uhm [long pause] it's very good

03 I: what kind of what kind of driving though big truck or small

$04 \quad$ R: $\quad \mid \begin{aligned} & \text { truck in factories } \\ & \text { eh no no no I have licence only car }\end{aligned}$

05 I: $\quad$ you have a car licence

06 R: licence right

What would a 'cultural' explanation accounting for R's minimal response in turn 2 look like? Bringing R's ethnic and cultural origin to the forefront of analysis, it would invoke the cultural stereotype of Asians as submissive and non-confrontational. But such a reading is difficult to justify when the question to which turn 2 responds is itself not confrontational. An alternative line of explanation, looking at the linguistic and situational asymmetries, is certainly more sophisticated. We could attribute R's failure to understand the force of I's question in turn 1 to his inadequate linguistic knowledge. This seems convincing as, in turn 2 , we see ' $R$ ' providing a minimal response which is punctuated with a long stretch of silence. This response is judged unsatisfactory by the interviewer, as can be noticed in turn 3 where the question is paraphrased for the benefit of ' $R$ '. This suggests ' $I$ ' recognises that $R$ 's problem is a linguistic one, and this is confirmed later as ' $R$ ' offers an acceptable answer in response to the reformulated question.

Should we decide to take our analysis of 'miscommunication' a bit further, it is possible to argue that the communicative problem does not squarely lie with ' $R$ '. 'I' can be held partly responsible for the way he phrases the question. The ambiguity surrounding the question relates to 'driving', which occupies the subject position. It could therefore be taken to mean either 'quality of driving' or 'driving certain types of vehicle' - the latter being the most preferred reading under the circumstances. Is this failure on the part of the interviewer to disambiguate the force of his question also a matter of linguistic incompetence? Perhaps the choice of the term 'type', rather than 'kind', could have made it comprehensible. Perhaps an alternative phrasing such as 'what kind/type of vehicle have you been driving?' would have been more straightforward.

\footnotetext{
${ }^{11}$ In the data represented here, the following transcription conventions are used:

() inaudible speech

[] extralinguistic details such as 'laughter', 'pause', etc.

i overlaps
} 
We know that in the context of selection interviews questions often have a hidden purpose which the candidate has to work out for him/herself. Under such an assumption, the present interviewer's 'indirect' questioning behaviour can be legitimated or at least apprehended. But given that ' $R$ ' has problems with decoding the linguistic structure in this instance, why does he go on to provide an answer instead of making a request for clarification? There are several competing explanations. In situational terms, it means that all interview settings are marked by a procedural power differential, where to ask questions of the powerful participant can be seen as face-threatening. Additionally, because it is an interview situation involving a nonnative speaker of English, to indicate non-comprehension can potentially lead to a negative evaluation of ' $R$ '.

At another level, it is theoretically viable to assume that an interviewee in fact understands the question but decides to 'flout' (in the Gricean sense) the conventions of the interview game. This explanation is not tenable in the case under discussion, however, as two turns later (in turn 4) 'R' does provide an 'acceptable' response. The point I want to make is that if a member of the majority group were to provide a response similar to that of ' $R$ ', this would most likely be interpreted as 'flouting' rather than as evidence of linguistic incompetence or unfamiliarity with interview norms. This begs the question: why should an instance of miscommunication, when it involves participants from different ethnic/cultural backgrounds, be treated as resulting from culture-specific behaviour whereas the same instance of mismatch, when it involves participants from the same 'culture', become labelled as a challenge? The problem, as I see it, is not just related to the relative weighting of one framework over another, it also concerns the set of explanatory presumptions which researchers entertain when dealing with monocultural and intercultural communicative settings.

Let me take this issue further by re-interpreting a familiar case study (example 2) taken from Gumperz et al. (1979), followed by a comparison with a parallel situation in my own data (examples 3 and 4). Example 2 involves Sandhu (SN) who arrived in Britain in the early sixties and had several manual jobs in factories, worked as a bus conductor, and at the time of the interview is working in a training resource centre. He has now applied for a post of assistant librarian and in the interview is asked what his present job is about. Apart from the interviewee Sandhu, the extract represented here involves two interviewers, I2 and I3.

\section{Data Example 2}

$01 \quad$ I2: You say you're very busy eh in your present job [pause] what exactly do you do [pause] I mean what are your duties day by day

$02 \mathrm{SN}$ : Well we've to eh receive the visitors [pause] show them around and then we have to go out eh to the factories you know [pause] eh sometimes to attend the classes [pause] eh how to do erm cataloguing classification

03 I2: Erm what are you familiar within the field of cataloguing and classification 
$\mathrm{SN}$ Well it it depends on what sort of eh classification college is using and [pause] I'm sure erm this Middleton College will be using the decimal classification uhm which I've done you know in the college

I3: Can I move on to the question of handling er library users [pause] this is mentioned little bit in the job description erm [pause] how well do you get on with people mister Sandhu [pause] I mean how much experience have you got of getting on with people generally SN: Well I I think I'm very good so far as getting with the other people I'm very very good particularly with the students $[\ldots]$

Following Gumperz et al., one could account for the miscommunication in turn 2 in terms of culture-specific ways of structuring information. I would like to suggest to look at it as a case of 'activity-specific' mismatch in the sense that interview talk can go wrong, whether or not participants are culturally different. This is not to deny that interviews are shaped and influenced by culture-specific preferences, but it is possible to argue that even in cases where interviewee and interviewer have the same cultural background, perceptions about what is (not) 'acceptable' in the interview context may differ. What Sandhu does, it seems to me, is follow the rules of the interview game, as he presents himself favourably both in relation to how knowledgeable he is with regard to cataloguing and classification and in relation to how good he is in human relationships.

As in example 1, we should recognise how this instance of mismatch in example 2 is jointly constructed. For instance, we could point at the lack of clarity in the manner in which the interviewer conflates two different questions (turns 1 and 5), which result in Sandhu supplying incomplete responses. The first question (turn 1) has a two-fold function, but Sandhu chooses to focus on one aspect - 'what exactly do you do' - while answering the second aspect of the interviewer's question - 'what are your duties day by day' - only marginally. In turn 3, the question about cataloguing and classification is asked in order to enable Sandhu to display his technical knowledge about the job of librarianship. Given this hidden purpose, the question - 'what are you familiar with'- is fairly general and is open to several interpretations. Again, Sandhu answers the question marginally and it is not clear why he starts his answer by saying 'it depends'. In turn 5, the question about handling library users again has two aspects: 'how good' he is and 'how much experience' he has. Sandhu's answer is partial in that his answer is about 'how good' he is, completely overlooking the other aspect of the question. Even in answering the first part, he makes no reference to his actual experience.

Let us now consider an excerpt from my own data which involves a situation parallel to example 2. Samal (SL) is interested in joining the British Social Security department as a clerical assistant. Before arriving in Britain he worked in Bangladesh as a school teacher and as an assistant clerk in an insurance firm. His previous employment in Britain includes twelve years in the Bradford City Transport Company and, subsequently, a job as a machine operator. The excerpt begins with the interviewer (I1) asking the candidate a question about the present job. 


\section{Data Example 3}

01 I1: Erm you worked as an assistant clerk for a few months in an insurance | company

02 SL: | Yeah yes I did

03 I1: What did that job entail

04 SL: Erm [pause] I had to copy sometimes er eh the letters sending somewhere [pause] and also quite a bit er eh records and so on [pause] sometimes I work in wages department

05 I1: Yes I see [pause] did you do that job after the school teaching

06 SL: Eh yes / after teaching

07 I1: $\quad$ Yes erm did you find anything in about the job particularly interesting

08 SL: Erm in my that job

09 I1: Mhm hm

10 SL: Well eh job yes [pause] the clerical job was very interesting [laughs] but in education department [pause] eh is is also inte interesting [pause] but clerical job was more interesting than the teaching

11 I1: What was it about the clerical job that you found interesting

12 SL: Erm to [pause] eh almost everything I did er interesting

13 I1: You found the the whole job interesting itself

14 SL: Yeah

15 I1: Right then I would like to introduce you [...]

We can notice the casual-conversational style of the interview, manifested in the turn-taking system, interruptions initiated by SL and the use of back-channelling. This conversational style overlaps with the content of Samal's response. Instead of providing a specific judgemental answer when asked about which of the two previous jobs he liked most and why, Samal responds with a factual account which offers no comparative evaluation of the two jobs. Maintaining that he liked both jobs equally well, he gives the impression that it was not a dissatisfaction with teaching which led to a shift in career. In turns 11 and 13, the interviewer tries to delve into the actual nature of the clerical job, but in both cases SL provides minimal responses. In both examples 2 and 3, questions about the current job are asked. In the context of selection interviews in general, an interviewer expects the candidate to offer a response which includes those bits of work from among the host of other things, which are not only 'interesting' but also 'relevant' to the prospective job in question. At a less abstract level, there is the expectation that the candidate will touch upon the transferable skills s/he could bring to the new job. Both SN and SL do not offer 'satisfactory' responses to these expectations, which can be partly seen in the way the interviewers in both cases stay on the topic for a while and make the implicit expectations transparent.

Let us now turn to another focal aspect of job interviews, i.e. how candidates' profiles can be constructed negatively. In example 4 below, which also involves Samal (SL), the interviewer (I2) asks a question of the following type: "Why did you do ' $x$ ' before and why do you want to do ' $y$ ' now?" 


\section{Data Example 4}

01 I2: Well mister Dixon started talking to you about jobs [pause] what I would like to ask you is some questions relating particularly to this job that you've applied for [pause] so the first question I would like to ask you is [pause] why have you applied for this job when when previously as I understand (unclear) you've been doing manual work for the last well for few years

02 SL: Yeah er [pause] I came to almost it's not particularly myself I have seen some of my friends also in in similar situation [pause] erm I did try myself so so many places to get similar job in clerical or in office job or anything like that [pause] but could not succeed in [pause] and you know after all I applied in Bradford city transport and got a job and I was there about eleven twelve years I think [pause] and in sixty nine I had to go to Bangladesh and I left the job [pause] erm when I came back erm I registered myself in the job centre and they erm send me a letter to go to (unclear) because I had a bit experience about the machine operating so I went there and I had a job you know and it was a very good job

03 I2: Oh yes but

04 SL: In er something else beside is [pause] while there applied and the the factory you know international factory is closed at eighty two

05 I2: Mhm

06 SL: Close down so I had no job so this in eh (unclear) there is community college and they are running the course [pause] A B L E course access to bilingual employment [pause] which means already you know no eh eh two languages they will improve ehm your skill [pause] and I applied there and I was eh er I almost almost finish [pause] the course is almost finished [pause] so I have got some weeks more extra experience to getting a new job you know

07 I2: Having been to (unclear) you say you're bilingual erm is there a particular skill that you feel would help you in the job and if so how

08 SL: Ehm [pause] they they teach there er about about various organisation [pause] how does it run and so on you know (unclear) [pause] and also er teach English [pause] I think my English has erm improve a lot than I have before [pause] and also how to do the er from English to Bengali [pause] Bengali to English [pause] and how to er translate and everything [pause] they do try to develop [coughs]

Rather than giving a profile of himself to show convincingly how he would fit into the job he is applying for, SL offers a narrative of past experience. He opts for 'telling' - not 'selling' - the story of his work life, even to the extent of interrupting the interviewer (turns 3-4). The interviewer takes on the role of a passive listener until turn 7, where he dismisses the story-telling and reasserts his authority to ask questions 'relevant to the interview situation'. Once again, though, in turn 8, SL 
resorts to the story-telling mode as he offers a somewhat detailed description of the course content, instead of specifying a set of 'learned' skills which are transferable.

The above analysis, in sum, shows that although these interview situations can from one analytic angle straightforwardly be labelled and interpreted as intercultural, many of the communicative difficulties that occur in these situations do not easily lend themselves to an explanation exclusively based on the principle of cultural differences. A situational reading of the data seems to capture more closely the complexities - institutional and otherwise - involved in these contact situations.

\section{Migrant 'culture' in multicultural societies: from problem of 'difficulty' to politics of 'difference'}

The institutional and other complexities of the contact situations analysed above can at the societal level be traced in the discursive performances of first generation younger migrants such as the ones involved in the data. External forces such as underemployment among minority groups, perceived and real discriminatory tendencies in the job market, etc. seem to have partially shaped migrants' life experiences in multicultural societies. In light of this, rather than treat mismatches as exclusively resulting from 'cultural differences' or 'linguistic inadequacies', we need to consider how they reflect, following Bourdieu (1991), a kind of 'habitus' which is rooted, generally, in these life experiences. This comes out in the way the interviewees in my corpus choose to narrate believable stories in preference to conforming to the norms of the job interview format. As Bourdieu (1976: 654) points out:

\footnotetext{
"A speaker's linguistic strategies (tension or relaxation, vigilance or condescension, etc.) are oriented (except in rare cases) not so much by the chances of being understood or misunderstood (communicative efficiency or the chances of communicating), but rather by the chances of being listened to, believed, obeyed, even at the cost of misunderstanding (political efficiency or the chances of communicating)."
}

If some migrants share the features of a life history, having been through similar discontinuities in their employment patterns, it is quite possible that they will draw on their life histories in such gatekeeping encounters. So, when we detect a pattern in their talk, it may not simply be a question of structuring of information according to culture-specific norms, but rather a matter of what Raymond Williams (1981) calls 'structures of feeling' - how people narrate lived experiences. In my analysis, this type of explanation takes into account the potential structuredness of interindividually similar experiences, but at the same time reaffirms individual diversities.

It also leads us to move away from homogenising the migrant communities in terms of the significant 'other'. Some accounts of migrants do problematise the representation of migrant communities as homogeneous entities, but they do so along hypothetical lines. Cicourel (1982), for instance, takes it as a general characteristic of the situation of migrant workers that they have to live in two cultures. The resultant strain between the 'old self' and the 'new' is said to be 
manifested in problems of identity, social ambivalence, alienation and rejection. In this respect, Cicourel describes their situation as a 'no man's land' which is neither that of the migrant's country of origin nor that of his/her country of employment or residence. Similarly, Parris (1982: 4) summarises the migrant worker's position as follows:

"On the whole his (sic) existence is organised around two poles: his family and fellow countrymen, in a cultural environment resembling that of the country of origin; and his work and public life, in a culture unfamiliar to him or her."

This, for me, is an unsatisfactory account of a migrant's life world. The actual dichotomy between these two cultural environments is much more complex than what Parris seems to suggest. Only from an essentialist viewpoint can the two 'worlds' be held separate for one particular group of migrant workers. In addition, the interrelationship between these two 'worlds' will vary from one group to another. Moreover, the problems of identity, social ambivalence, alienation and rejection are just as well problems of the non-migrant population. In this sense the analytic concept of a homogeneous 'culture' is just as perilous for the non-migrant population which in intercultural studies tends to feature as 'culturally integrated individuals', and thereby often simply remains unnoticed.

It is worth pointing out that different notions developed within the existing literature on migrant communities are inadequate in their attempt to describe the situation of many different categories of migrants in a relatively similar way. Ekstrand et al. (1981), for instance, propose the notion of 'interculture' to refer to an intermediate culture which shares properties of both home culture and host culture, independent of whether those properties are shared between the cultures-in-contact. This notion of 'interculture' is very similar to the linguistic notion of 'interlanguage' (as proposed by Selinker 1972) referring to shared features of a speaker's native and target languages. But, as Skutnabb-Kangas \& Phillipson (1983: 71) point out, while 'interlanguage' can be typically seen as a transitory state with the target language as a goal, the notion of 'interculture' implies a rather stable state with none of the cultures in contact as a goal.

Neither of the above constructs - 'living in two cultures' or 'interculture' is powerful enough to capture the migrants' fluid identities. I hope my analyses have shown that it may however be possible to reconceptualise the notion of 'interculture', not alongside the concept of 'interlanguage', but in a way which captures the multi-faceted identities and diversified lived experiences of specific migrant groups. In order not to fall trap to the binary bias and the homogenisation of a group's 'cultural' practices, we need to take into account further markings within 'intercultures' such as 'urban youth culture', 'younger migrant culture', etc.. The interviewees in the data presented in this paper, in this sense, share a 'migrant outlook', but this outlook (values, interactive styles, etc.) cannot be captured by reference to either their 'culture of origin' or the 'culture of non-migrants'. 


\section{Conclusion}

In this paper I have raised questions about the 'cultural' emphasis in intercultural miscommunication analysis. Through analyses of intercultural data, I have shown how a selective characterisation of a communicative situation on the basis of different cultural attributes of the participants can only serve to reify cultural differences in an essentialist way. As an alternative, I have argued in favour of a discourse-analytic approach to the study of intercultural miscommunication as it allows us to interpret specific discursive practices of individual interactants both in terms of their cultural attributes and in the context of their societal and institutional role-relationships. One consequence of this is that intercultural analysis should not only aim at explicating the role which cultural differences play in intercultural miscommunication, but also at tackling the shifting nature of 'culture' in contemporary societies and what people actually do with cultural differences in reallife encounters. To conclude, the use of a unified view of 'culture' and, correspondingly, the thematisation of cultural differences in accounting for instances of 'intercultural miscommunication', both run the risk of stereotyping the field of intercultural communication research.

\section{References}

Asante, M.K., E. Newmark, and C.A. Blake (eds.) (1979) Handbook of intercultural communication. Beverly Hills: Sage.

Asante, M.K. and, W.B. Gudykunst (eds.) (1989) Handbook of international and intercultural communication. London: Sage.

Barth, Fredrik (1989) The analysis of culture in complex societies. Ethnos 54(3/4): 120-142.

Bennett, Tony, Graham Martin, Colin Mercer, and Janet Woollacott (eds.) (1981) Culture, ideology and social processes. London: Batsford (in association with The Open University Press).

Blommaert, Jan (1991) How much culture is there in intercultural communication? In J. Blommaert, and J. Verschueren (eds.), The pragmatics of intercultural and international communication. Amsterdam: John Benjamins.

Blum-Kulka, S., and E. Olshtain (1984) Requests and apologies: A cross cultural study of speech act realisation patterns (CCSARP). Applied Linguistics 5(3): 196-213.

Blum-Kulka, S., J. House, and G. Kasper (eds.) (1989) Cross-cultural pragmatics: Requests and apologies. Norwood, NJ: Ablex.

Bourdieu, Pierre (1976) The economics of linguistic exchanges. Social Science Information 16(6): 645-668.

Bourdieu, Pierre (1991) Language and symbolic power. Edited and introduced by John B. Thompson; Translated by Gino Raymond and Matthew Adamson. Cambridge, Mass: Polity Press.

Brislin, R. (1981) Cross-cultural encounters. New York: Pergamon. 
Brown, Penelope, and Stephen Levinson (1987) Politeness: Some universals in language use. Cambridge: Cambridge University Press.

Casmir, F.L. (ed.) (1978) Intercultural and international communication. Washington D.C.: University Press of America.

Cicourel, A.C. (1982) Living in two cultures: The everyday world of immigrant workers. In UNESCO: Living in two cultures: The socio-cultural situation of migrant workers and their families. Paris: The Unesco Press, 17-66.

Clifford, J., and G.E. Marcus (1986) Writing culture. Berkeley: University of California Press.

Condon, J.C., and F. Yousef (1975) An introduction to intercultural communication. Indianapolis, Indiana: The Bobbs-Merill Company.

Coupland, Nikolas, Howard Giles, and John Wiemann (eds.) (1991) "Miscommunication" and problematic talk. Newbury Park: Sage.

Drummond, Lee (1986) Are there cultures to communicate across? An appraisal of the 'culture' concept from the perspective of anthropological semiotics. In Simon P.X. Battestini (ed.), Georgetown University Roundtable on Languages and Linguistics. Washington, D.C.: Georgetown University Press, 215-225

Eisenstadt, S.N. (1989) Introduction: Culture and social structure in recent sociological analysis. In H. Haferkamp (ed.), Social structure and culture. Berlin: Walter de Gruyter, 5-11

Ekstrand, Lars Heneric, Sis Foster, Eva Olkiewicz, Miodrag Stankovski (1981) Interculture: Some concepts for describing the situations of Immigrants. Journal of Multilingual and Multicultural Development 2(4): 269-293.

Fairclough, Norman (1985) Critical and descriptive goals in discourse analysis. Journal of Pragmatics 9: 739-793.

Fairclough, Norman (1988) Michel Foucault and the analysis of discourse. CLSL Research Paper No. 10. Lancaster University.

Foucault, Michel (1984) The order of discourse. In M. Shapiro (ed.), Language and politics. London: Basil Blackwell.

Gramsci, Antonio (1981) Culture. In Tony Bennett et al. (eds.), 193-197.

Gudykunst, W.B. (ed.) (1983) Intercultural communication theory. Beverly Hills, CA: Sage.

Gudykunst, W.B. (1991) Bridging differences: Effective intergroup communication. Newbury Park, CA: Sage.

Gudykunst, W.B., and Y.Y. Kim (1984) Communicating with strangers: An approach to intercultural communication. New York: Random House.

Gudykunst, W.B., and Y.Y. Kim (eds.) (1988) Theories in intercultural communication. Newbury Park, Ca: Sage.

Gumperz, John (1978) The conversational analysis of interethnic communication. In E. Lamar Ross (ed.), Interethnic communication. Southern Anthropological Society, 13-31. 
Gumperz, John (1982) Discourse strategies. Cambridge: Cambridge University Press.

Gumperz, John (1992) Contextualisation revisited. In Peter Auer, and Aldo Di Luzio (eds.), The contextualization of language. Amsterdam: John Benjamins, 39-54.

Gumperz, John, and Deborah Tannen (1979) Individual and social differences in language use. In C. Fillmore, D. Kempler, and W. Wang (eds.), Individual differences in language ability and language behaviour. London: Academic Press.

Gumperz, John, Tom Jupp, and Celia Roberts (1979) Crosstalk. Southall: National Council for Industrial Language Training.

Hall, Stuart (1981) Cultural studies: Two paradigms. In Tony Bennett et al. (eds.), 19-38.

Hall, Stuart (1990) Cultural identity and diaspora. In Jonathan Rutherford (ed.), 222-237.

Henley, Nancy, and Cheris Kramarae (1991) Gender, power and miscommunication. In N. Coupland et al. (ed.), 18-43.

Kandiah, Thiru (1991) Extenuatory sociolinguistics: Diverting attention from issues to symptoms in cross-cultural communication studies. Multilingua 10(4): 345-379.

Levinson, Stephen (1979) Activity type and language. Linguistics 17: 365-399.

Moran, Robert T., and P. Harris (1991) Managing cultural differences. Houston: Gulf Publishing Co.

Moran, Robert T., and John R. Riesenberger (1994) Making globalization work. London: McGraw Hill.

Parris, R.G. (1982) General Introduction. In UNESCO: Living in two cultures: The sociocultural situation of migrant workers and their families. Paris: The Unesco Press, 1-14.

Peterson, R. (1979) Revitalising the culture concept. Annual Review of Sociology 5: 137-166.

Prosser, M.H. (1978a) Intercultural communication theory and research: An overview of major constructs. In B.D. Ruben (ed.), Communication yearbook volume II. New Jersey: ICA-Transaction Books.

Prosser, M.H. (1978b) The cultural dialogue: An introduction to intercultural communication. Washington: Houghton Miflin Company.

Roberts, Celia, and Srikant Sarangi (1993) 'Culture' revisited in intercultural communication. In T. Boswood, R. Hoffman, and P. Tung (eds.), Perspectives on English for professional communication. Hong Kong: City Polytechnic.

Rutherford, Jonathan (1990) Identity: Community, culture, difference. London: Lawrence and Wishart.

Samovar, L.A., and R.E. Porter (eds.) (1991) Intercultural communication: A reader. Belmont, Ca: Wadsworth.

Samovar, L.A., R.E. Porter, and N. Jain (1981) Understanding intercultural communication. Belmont, Ca: Wadsworth.

Sarangi, Srikant (1992) Power asymmetries in the study of NS-NNS discourse. Paper presented at $P A L A$ Conference, University of Gent, Belgium. 
Sarangi, Srikant (1994) Accounting for mismatches in intercultural selection interviews. Multilingua 13(1/2): 163-194.

Scollon, Ron, and Suzanne B.K. Scollon (1980) Linguistic convergence: An ethnography of speaking at Fort Chipweyan. New York: Academic Press.

Scollon, Ron, and Suzanne B.K. Scollon (1983) Face in interethnic communication. In Jack C. Richards, and Richard W. Schmidt (eds.), Language and Communication. London: Longman, 157-188.

Selinker, Larry (1972) Interlanguage. International Review of Applied Linguistics 10: 209-231.

Sherzer, Joel (1987) A discourse-centered approach to language and culture. American Anthropologist 89: 295-309.

Singh, Rajendra, Jayant Lele, and Gita Martohardjono (1988) Communication in a multilingual society: Some missed opportunities. Language in Society 17: 43-59.

Skutnabb-Kangas, T., and R. Phillipson (1983) Intercommunicative and intercultural competence. Rolig-Papir 28. Roskilde Universitets Center.

Street, Brian V. (1993) Culture is a Verb: Anthropological aspects of language and cultural process. In David Graddol, Linda Thompson, and Mike Byram (eds.), Language and culture. Clevedon: BAAL and Multilingua Matters, 23-43.

Stubbs, Michael (1983) Discourse analysis: The sociolinguistic analysis of natural language. Oxford: Basil Blackwell.

Thomas, Jenny A. (1983) Cross-cultural pragmatic failure. Applied Linguistics 4(2): 91-112.

Thornton, R (1988) Culture: A contemporary definition. E. Boonzaeir, and J. Sharp (eds.), Keywords. Cape Town: David Philip.

Williams, Raymond (1981) The analysis of culture. In Tony Bennett et al. (ed.), 43-52.

Wuthnow, R., J.D. Hunter, Albert Bergesen, and Edith Kurzweil (1984) Cultural analysis: The work of Peter L. Berger, Mary Douglas, Michel Foucault and Jurgen Habermas. London: Routledge and Kegan Paul. 